\title{
The development and validation of the psychological capital questionnaire for patients with Cancer the psychological capital questionnaire
}

\author{
Chun Ying Cui, Yu Wang, Ying Zhang, Siqi Chen, Nan Jiang and Lie Wang*
}

\begin{abstract}
Background: Studies increasingly show that positive psychological constructs affect the mental health of cancer patients. However, most scales that measure hope, resilience, optimism and self-efficacy have been developed based on general populations. The aim of our study was to develop a psychological capital (PsyCap) questionnaire for patients with cancer (PCQ-C) to gauge their mental state more accurately.

Methods: The items for the scale were selected by comprehensive literature review and semi-structured interviews, and the relevant terms were screened by an expert panel. A pilot study was then conducted on 202 patients to reduce the item pool, and the reliability and validity of the scale were evaluated using 500 completed questionnaires. The testretest reliability was then assessed using a subsample of 100 patients. Finally, the completed questionnaires of 229 patients with breast cancer were used to assess the criterion validity of the PCQ-C, including measures of depression and anxiety.

Results: Item reduction and exploratory factory analysis resulted in 24 items for self-efficacy, hope, resilience and optimism, accounting for $56.72 \%$ of the variance. The Cronbach's alpha for the scale was 0.886 , and the test-retest reliability was 0.825 . PsyCap showed a significant negative correlation with both depression $(r=-0.631, P<0.01)$ and anxiety $(r=-0.601, P<0.01)$.
\end{abstract}

Conclusion: The PCQ-C can objectively evaluate PsyCap in cancer patients and exhibits good psychometric properties.

Keywords: Cancer, Psychological capital, Questionnaire, PCQ-C, Development

\section{Background}

Several state-like positive psychological constructs have been identified in the fields of positive psychology and psycho-oncology $[1,2]$. The most common state-like constructs are hope (persevering towards goals and when necessary, redirecting paths to reach those goals), resilience (withstanding problems and adversity, and rebounding),

\footnotetext{
* Correspondence: liewang@cmu.edu.cn

Department of Social Medicine, School of Public Health, China Medical University, No.77 Puhe Road, Shenyang North New Area, Shenyang, Liaoning 110122, People's Republic of China
}

optimism (making a positive attribution about reaching goals) and self-efficacy (having confidence to take on and succeed at challenging tasks) [3, 4], in addition to wisdom, gratitude, courage, well-being and forgiveness [4]. Studies increasingly show that positive psychological constructs are significantly associated with patients' quality of life, mental health and satisfaction with life, particularly among cancer patients $[2,5-8]$. Thus, enhancing these constructs is crucial for the well-being of cancer patients.

Cancer is the leading cause of death globally, and according to World Health Organization (WHO) reports, 
it is the first or second leading cause of death among those younger than 70 years in most countries [9]. Cancer incidence and mortality rates have increased rapidly across countries of all income levels. In addition, cancer diagnosis and subsequent treatment are highly stressful for patients, which often leads to negative emotions and deterioration in mental health [10]. Studies show that cancer patients with similar disease severity and treatment status often display significantly different levels of psychological stress, likely due to disparities in terms of hope, resilience, optimism and self-efficacy [5-8]. Depression and anxiety are the most common psychological distress among cancer patients [11]. A growing number of studies have reported that positive psychological resources, as protective factors, can help cancer patients adjust and manage disease, thereby effectively attenuating psychological distress and mental problems $[12,13]$. For instance, Yang et al. found that the integrated effects of hope, resilience and optimism were significantly and negatively associated with depression and anxiety among patients with cancer [14]. Therefore, evaluating the positive psychological constructs can help assess the mental health of cancer patients during treatment.

However, the current evaluation scales are based on participants with depression and anxiety or the general population $[15,16]$. For instance, the Connor Davidson Resilience Scale (CD-RISC) was developed based on a sample with anxiety symptoms [17]. In addition, the Snyder Hope Scale was broadly adapted to measure the level of hope among heathy individuals $[18,19]$. Some aspects of these state-like variables and integration processes in cancer patients are significantly different from those in other populations due to the complex treatment and potential fatality in the former [20-22]. Ye et al. surmised that cancer patients need to learn new skills to self-manage fatigue, pain, nausea, and constant negative emotion concerning death throughout the process of treatment [21]. Therefore, it is crucial to develop scales specific to cancer patients to gauge their mental health with greater reliability. Luthans et al. [23] proposed the concept of psychological capital (PsyCap), which consists of hope, resilience, self-efficacy and optimism and shows a relatively stronger relationship to performance and job satisfaction than any of the individual facets. The aim of our study was to develop and validate a PsyCap questionnaire for cancer patients to assess their mental state and the ability to self-manage and "bounce back" after cancer diagnosis and treatment.

\section{Methods}

\section{Survey participants}

The survey was administered to cancer patients across five cities in northeast China between September 2020 and February 2021. The inclusion criteria for patients were as follows: 1) cancer diagnosis, 2) awareness of the disease, 3) fluency in Chinese, and 4) 18 years or older. Patients with other severe diseases (such as cardiovascular disease, history of psychiatric problems, or cognitive and intellectual disorders) were excluded. The participants were interviewed to obtain all relevant information. The study was approved by the Ethics Committee on Human Experimentation of China Medical University, and all participants provided written consent prior to the survey.

\section{Measurements \\ Depression}

Depression was evaluated using the Chinese version of the self-reported Patient Health Questionnaire-9 (PHQ-9) [24] over a period of two weeks. The PHQ-9 includes nine items related to anhedonia, sadness, sleep, fatigue, appetite, feelings of worthlessness, concentration, motor skills and death. Higher scores indicate higher levels of depression. The Cronbach's alpha for the PHQ-9 is 0.869 .

\section{Anxiety}

Anxiety was assessed using the Chinese version of the self-reported Generalized Anxiety Disorder-7 (GAD-7) [25] over two weeks. The GAD-7 contains seven items related to nervousness, control, worry, relaxation, restlessness, irritability and fear. Higher scores indicate higher levels of anxiety. The Cronbach's alpha for the GAD-7 is 0.895 .

\section{Statistical methods \\ Item generation}

The preliminary questionnaire was developed on the basis of a literature review and semi-structured and indepth interviews with 30 cancer patients. Following discussion with an expert panel of psycho-oncologists and grouping/excluding any similar or ambiguous items, a 64-item questionnaire was drafted. Each item was scored on the basis of a five-point Likert scale that varies from " $1=$ very strongly disagree" to " $5=$ very strongly agree". A pilot survey was then carried out on 202 cancer patients to assess the validity and clarity of the questionnaire, and the number of items was reduced to 44 .

\section{Item reduction and scale development}

A total of 505 cancer patients were recruited on the basis of the inclusion and exclusion criteria, and their demographic and clinical data were collected. The intercorrelation between the items was calculated based on the data generated from the survey. Low interrelation items $(r<0.1)$ were excluded, and the highly interrelated items $(r>0.7)$ were analysed further. The least clinically 
relevant item was excluded due to high association with the same underlying dimension theoretically [26].

\section{Construct validity}

Exploratory factor analysis (EFA) was used to assess construct validity to identify the key components. The suitability of EFA was assessed by Bartlett's test, KaiserMeyer-Olkin (KMO) measure and eigenvalue cut-off value $>1$. The items with total correlation $<0.3$, factor loading $<0.5$ on one factor, communality $<0.4$ and loaded into two factors were excluded [27]. Structural equation modelling (SEM) was used to perform confirmatory factor analysis (CFA). After optimizing all parameters, the $\chi^{2}$ test and measures for good of fit were reviewed $[28,29]$.

\section{Reliability}

Cronbach's alpha was used to evaluate the internal consistency for the total scale [29]. The test-retest ability among 100 cancer patients with a four-week interval between the tests was measured by Spearman's correlation analysis. The criterion validity of the PCQ-C, including depression and anxiety, was evaluated based on the questionnaires completed by 227 breast cancer patients.

\section{Results}

\section{Participants}

A total of 505 cancer patients completed the questionnaires, and five were subsequently excluded on account of considerable missing data (>30\%). Therefore, the effective response rate was $99 \%$. The mean age of the participants was 58.03 years (SD: 12.35 ), and $56.2 \%$ of the participants were females and $43.8 \%$ males. Approximately $76 \%$ of the patients were married/cohabiting. Furthermore, $76.2 \%$ of the patients had a high school level or lower educational level, and $82.8 \%$ were employed. Approximately $46.6 \%$ of the participants had a monthly income over 3000 yuan. The proportions of patients with lung cancer, breast cancer and haematological cancers were $20.8,15.2$ and $14.8 \%$, respectively (Table 1).

\section{Construct validity \\ Exploratory factor analysis}

Five items were deleted owing to item-total correlation $<0.3$. Therefore, all 39 items were analysed using EFA, which initially generated six factors (eigenvalue $>1$ ) with a total explained variance of $56.26 \%$. (KMO $=0.951$, Bartlett's test of sphericity $\chi^{2}=9662.41, \mathrm{df}=741, P<0.001$ ). However, the fit was poor, and 10 items were excluded due to low factor loading $(<0.5)$ and cross-loading on two factors. The remaining 29 items were analysed further, and 5 were extracted, explaining $57.21 \%$ of the variance $\left(\mathrm{KMO}=0.941\right.$, Bartlett's test of sphericity $\chi^{2}=$
Table 1 Demographic characteristics of the participants $(n=$ 500)

\begin{tabular}{|c|c|c|}
\hline \multicolumn{2}{|l|}{ Variables } & \multirow{2}{*}{$\frac{\mathbf{N}(\%)}{58.03 \pm 12.35}$} \\
\hline Age & Mean \pm SD & \\
\hline \multirow[t]{2}{*}{ Gender } & Male & $219(43.8)$ \\
\hline & Female & $281(56.2)$ \\
\hline BMl & Mean \pm SD & $23.55 \pm 4.72$ \\
\hline \multirow[t]{3}{*}{ Marital status } & Married/cohabiting & $383(76.6)$ \\
\hline & Single/separated/divorced/widowed & $74(14.8)$ \\
\hline & Missing & $43(8.6)$ \\
\hline \multirow[t]{4}{*}{ Education } & High school or below & $363(72.6)$ \\
\hline & Some college & 68 (13.6) \\
\hline & College or above & $41(8.7)$ \\
\hline & Missing & $28(5.6)$ \\
\hline \multirow[t]{3}{*}{ Employment status } & Employed & $414(82.8)$ \\
\hline & Unemployed/temporary workers & $62(12.4)$ \\
\hline & Missing & $24(4.8)$ \\
\hline \multirow[t]{4}{*}{ Monthly income } & $<3000$ & $233(46.6)$ \\
\hline & $3000-5000$ & $156(31.2)$ \\
\hline & $\geq 5000$ & 79 (15.8) \\
\hline & Missing & $32(6.4)$ \\
\hline \multirow[t]{10}{*}{ Cancer type } & Hematologic & $74(14.8)$ \\
\hline & Colon & $40(8.0)$ \\
\hline & Lung & $104(20.8)$ \\
\hline & Cervical & $24(4.8)$ \\
\hline & Breast & $76(15.2)$ \\
\hline & Esophagus & $17(3.4)$ \\
\hline & Head and neck & $24(4.8)$ \\
\hline & Gastric & $22(4.4)$ \\
\hline & Other & $37(7.4)$ \\
\hline & Missing & $82(16.4)$ \\
\hline
\end{tabular}

6622.52, $\mathrm{df}=406, P<0.001$ ). One factor (two items) was removed, as the explained variance of $4.59 \%$ (eigenvalue of 1.36) was lower than 5\% [27]. Three items were omitted due to insignificant factor loading $(<0.5)$ and low community $(<0.4)$. After a final round of EFA on the remaining 24 items, 4 were produced and explained $56.72 \%$ of the variance, and each factor was over $10 \%$ of the explained variance $(\mathrm{KMO}=0.925$, Bartlett's test of sphericity $\left.\chi^{2}=5382.19, \mathrm{df}=276, P<0.001\right)$ (Table 2$)$.

Based on the EFA results, the first factor contained six items and was identified as hope concerning the expectations of a cancer cure and confidence in fighting the disease. The second factor was defined as self-efficacy and contained six items related to the ability to cope with treatment-related side effects. Six items loaded on the third factor, which was identified as resilience, adaptability and past achievements. Finally, six items described 
Table 2 Results of the principal components analysis of 24 items

\begin{tabular}{|c|c|c|c|c|}
\hline Items & Factor 1 & Factor 2 & Factor 3 & Factor 4 \\
\hline I can still experience the joys of life after being diagnosed with cancer & 0.575 & & & \\
\hline Do something special for myself to make life better & 0.652 & & & \\
\hline Help other patients cope with cancer and treatment & 0.622 & & & \\
\hline Divert my attention from the disease by focusing on other important things in life & 0.769 & & & \\
\hline Find a way to help myself through this difficult time & 0.771 & & & \\
\hline I can overcome physical distress or relieve fatigue by doing something & 0.762 & & & \\
\hline I treat disease with a positive attitude & & 0.652 & & \\
\hline I never give up even if the chance of cure is low & & 0.729 & & \\
\hline My faith helps me through my illness & & 0.675 & & \\
\hline I can give and receive love and care from others & & 0.632 & & \\
\hline I should perform positive actions to navigate through the disease & & 0.708 & & \\
\hline I believe that we can fight diseases as long as we work hard & & 0.681 & & \\
\hline I like to challenge myself with new and difficult things & & & 0.716 & \\
\hline I still think I'm a very energetic person when sick & & & 0.715 & \\
\hline My daily life is full of things that interest me & & & 0.715 & \\
\hline I have a tenacious personality even after the cancer diagnosis & & & 0.669 & \\
\hline I can concentrate and think clearly under the pressure of illness & & & 0.647 & \\
\hline I can make unusual or difficult decisions & & & 0.602 & \\
\hline If I think I am going to fail, it is going to happen & & & & 0.584 \\
\hline The effect of disease treatment rarely follows the trend I expect & & & & 0.583 \\
\hline I often worry about my health & & & & 0.706 \\
\hline I hardly expect good things to happen to me & & & & 0.556 \\
\hline I feel tired most of the time & & & & 0.666 \\
\hline I feel very lonely or helpless after cancer diagnosis & & & & 0.633 \\
\hline Eigenvalue & 3.826 & 3.693 & 3.641 & 2.452 \\
\hline$\%$ of variance & 15.944 & 15.387 & 15.170 & 10.218 \\
\hline
\end{tabular}

Factor 1, self-efficacy; factor 2, hope; factor 3, resilience; factor 4, optimism

optimism related to positive attitudes. The eigenvalues of these four factors were $3.826,3.693,3.641$ and 2.452, respectively.

\section{Confirmatory factor analysis}

The goodness-of-fit of the four-factor structure of the PCQ-C tool was determined using AMOS version 17.0, which revealed excellent fit indices $\left(\mathrm{X}^{2} / \mathrm{df}=2.072\right.$, GFI $=$ 0.925, RMSEA $=0.046, \mathrm{CFI}=0.951, \mathrm{NFI}=0.910, \mathrm{TLI}=$ 0.943, AGFI $=0.906$ and IFI $=0.951)$ [30-32]. According to the modification indices, several paths of covariance between items and error were added to enhance the fit indices (Fig. 1).

\section{Internal consistency, test-retest reliability and criterion- related validity Internal consistency}

The Cronbach's alpha coefficient $(\alpha)$ for the total scale was 0.886 , which is considerably over the recommended index of 0.70 [32]. The internal consistency and correlation value of corrected items to the total correlation of items to their loading subscale are shown in Table 3.

\section{Test-retest reliability}

Test-retest reliability testing of the scale was conducted on the data collected from 120 cancer patients with a four-week interval between the tests. The response rate was $83.3 \%$ (100 participants) since twenty patients rejected further investigation. The mean age of the participants was 57.04 years (SD: 12.32 ); $55 \%$ were females and $45 \%$ were males. The mean PsyCap-C scores at the first and second assessment occasions (T1 and T2) were $3.81(\mathrm{SD}=0.51)$ and 3.64 $(\mathrm{SD}=0.46)$, respectively. There was a significant correlation between the two periods (PsyCap-C: $r=0.825, P<0.001$; self-efficacy: $r=0.824$, $P<0.001$; hope: $r=0.836, P<0.001$; resilience: $r=0.811$, $P<0.001$; optimism: $r=0.807, P<0.001$ ), and Cronbach's alpha coefficient $(\alpha)$ was adequate at both time points (Table 4). 


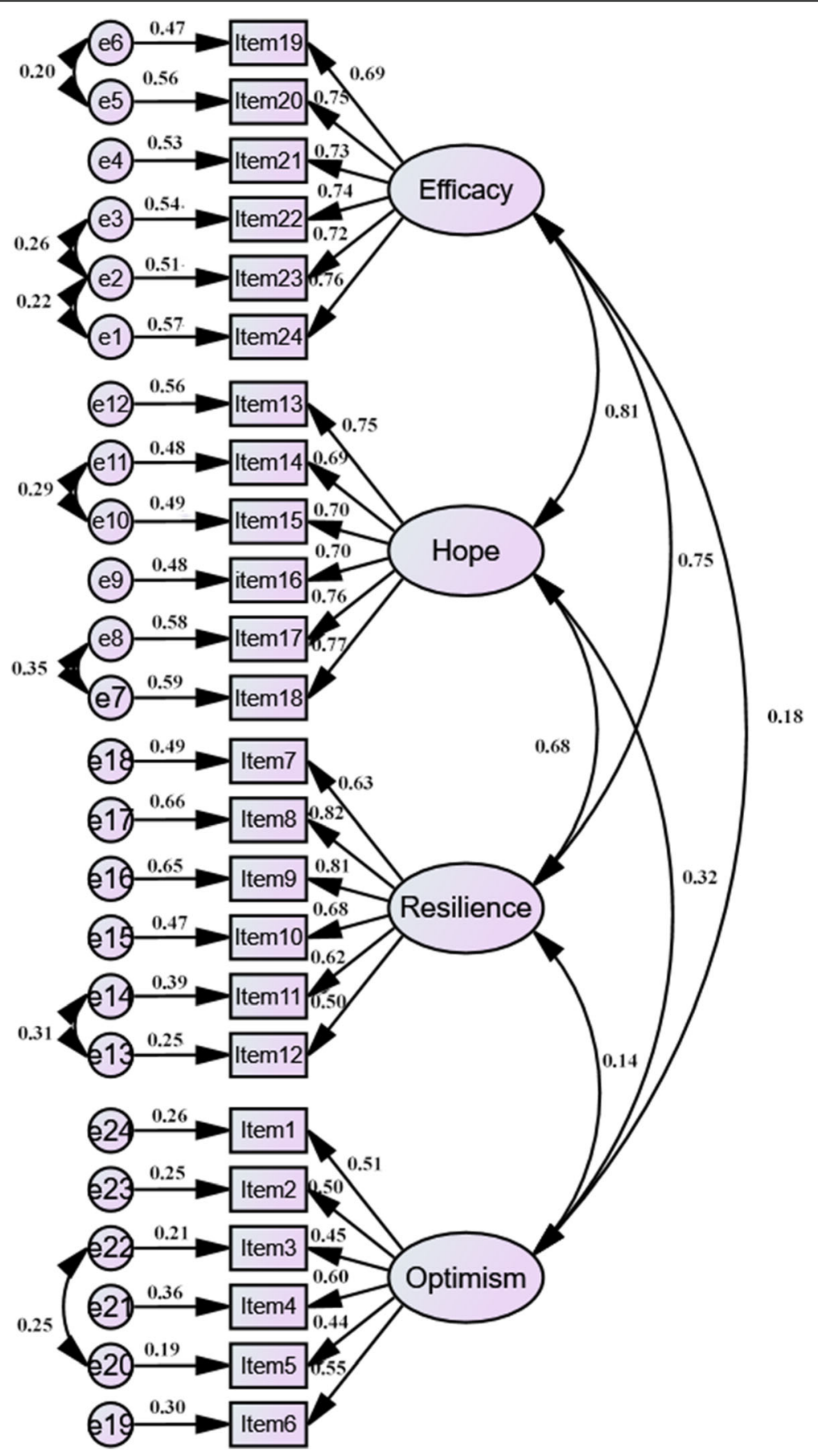

Fig. 1 Final CFA model of the PCQ-C

\section{Criterion-related validity}

Among 227 patients with breast cancer, the mean scores of depression and anxiety were $6.83(\mathrm{SD}=4.87)$ and $5.68(\mathrm{SD}=$ 4.23), respectively. PsyCap-C and the four individual dimensions showed a significant association with depression (PsyCap-C: $r=-0.631, P<0.01$; self-efficacy: $r=-0.536, P<0.01$; hope: $r=-0.525, P<0.01$; resilience: $r=-0.479, P<0.01$; optimism: $r=-0.400, P<0.01$ ) and anxiety (PsyCap-C: $r=-$
0.601, $P<0.01$; self-efficacy: $r=-0.502, P<0.01$; hope: $r=-$ 0.477, $P<0.01$; resilience: $r=-0.449, P<0.01$; optimism: $r=$ $-0.416, P<0.01)$.

\section{Discussion}

Evaluation of PsyCap consisting of hope, self-efficacy, optimism and resilience can improve the quality of life of cancer patients, help them cope with mental problems 
Table 3 Item to total correlation and Cronbach's alpha for the scale

Scale/items

Self-efficacy

19. I can still experience the joys of life after being diagnosed with cancer

20. Do something special for myself to make life better

21. Help other patients cope with cancer and treatment

22. Divert my attention from the disease by focusing on other important things in life

23. Find a way to help myself through this difficult time

24. I can overcome physical distress or relieve fatigue by doing something Hope

13.I treat disease with a positive attitude

14.I never give up even if the chance of cure is low

15. My faith helps me through my illness

16. I can give and receive love and care from others

17. I should perform positive actions to navigate through the disease

18. I believe that we can fight diseases as long as we work hard Resilience

7. I like to challenge myself with new and difficult things

8. I still think I'm a very energetic person when sick

9. My daily life is full of things that interest me

10. I have a tenacious personality even after the cancer diagnosis

11. I can concentrate and think clearly under the pressure of illness

12. I can make unusual or difficult decisions

Optimism

1. If I think I am going to fail, it is going to happen

2. The effect of disease treatment rarely follows the trend I expect

3. I often worry about my health

4. I hardly expect good things to happen to me

5. I feel tired most of the time

6. I feel very lonely or helpless after cancer diagnosis

PsyCap-C

${ }^{* *} P<0.01$

PsyCap-C, Psychological Capital to Cancer

\section{Corrected item to total correlation Cronbach's alpha}

0.880

$0.763^{* *}$

$0.758^{* *}$

$0.708^{* *}$

$0.652^{* *}$

$0.648^{* *}$

$0.712^{* *}$

0.879

$0.782^{* *}$

$0.598^{* *}$

$0.751^{* *}$

$0.639^{* *}$

$0.720^{* *}$

$0.720^{* *}$

$0.456^{* *}$

$0.735^{* *}$

$0.676^{* *}$

$0.602^{* *}$

$0.653^{* *}$

$0.576^{* *}$

$0.311^{* *}$

$0.312^{* *}$

$0.337^{* *}$

$0.416^{* *}$

$0.306^{* *}$

$0.450^{* *}$

Table 4 Cronbach's alpha and test-retest reliability at the first and second assessment occasions

\begin{tabular}{llll}
\hline Scale & Cronbach's alpha T1 & Cronbach's alpha T2 & Test-retest reliability \\
\hline Self-efficacy & 0.880 & 0.894 & $0.824^{* * *}$ \\
Hope & 0.879 & 0.894 & $0.836^{* * *}$ \\
Resilience & 0.839 & 0.841 & $0.811^{* * *}$ \\
Optimism & 0.696 & 0.754 & $0.807^{* * *}$ \\
PsyCap-C & 0.886 & 0.911 & $0.825^{* * *}$ \\
\hline
\end{tabular}

${ }^{* * *} P<0.001$

$\mathrm{T} 1$, time $1 ; \mathrm{T} 2$, time 2 
(depression and anxiety), and even relieve cancer-related fatigue $[5-8,33]$. However, the scales used thus far are either generic PsyCap tools such as the PCQ [23], which do not represent the unique psychological condition of cancer patients, or one-dimensional scales such as the Cancer Behaviors Inventory (CBI) [22], which neglects all psychological propensities apart from coping ability. Given that PsyCap may have a relatively stronger association with positive effects in cancer patients compared to the four individual facets, we developed a questionnaire based on both patients' and experts' views of the disorders. This is the first questionnaire that was developed to assess PsyCap specifically in cancer patients. The items for the scale were selected on the basis of a literature review and semi-structured patient interviews wherein they expressed their views regarding the disease [34]. Subsequently, psycho-oncology experts reviewed and assessed the selected items, which were then validated on 500 cancer patients using EFA and CFA, which indicated good internal consistency and test-retest reliability on the PCQ-C. Finally, the PCQ-C has 24 items, and a four-factor structure is identified.

The final version of the PCQ-C consists of four domains: hope (six items), self-efficacy (six items), resilience (six items) and optimism (six items). Hope is a positive expectation about achieving a possible and significantly good future in fighting cancer [35]. Selfefficacy is defined as a positive belief of individual competence to deal with treatment-related side effects or achieve desired goals in the face of cancer [36]. Resilience is expressed in an individual's capacity to successfully recover and maintain their mental health in the context of disease events [37]. Optimism is considered the degree of general expectation that positive outcomes will happen rather than bad things in the face of cancer diagnosis and treatment $[38,39]$. In our study, PsyCap-C and the four individual dimensions were significantly associated with depression and anxiety, which suggested that the scale had good construct validity.

\section{Clinical implications}

Our study has developed the first objective measure of PsyCap specifically for cancer patients. We hope that it can be applied in the clinical setting to monitor PsyCap as part of cancer care and in psychological interventions as a self-report outcome measure.

\section{Study limitations}

There were several limitations in the current study. First, the cross-sectional design precluded the verification of developmental stability or change in PsyCap for the sample. Therefore, the time-dependent changes in the sensitivity of the PCQ-C will have to be assessed in future studies. Second, although the PCQ-C was based on
PsyCap theory, which mainly originated from studies in the West, we developed and validated this scale among Chinese cancer patients. Therefore, the applicability of the PCQ-C should be tested across different ethnicities. Third, our study lacked convergent validity for the scale and did not compare the PCQ-C with other scales. The self-reported data in our study might also have resulted in bias. Finally, items in the optimism dimension presented low item-total correlations compared to other items and will have to be revised.

\section{Conclusions}

The PCQ-C is a reliable tool to objectively measure PsyCap among cancer patients based on self-efficacy, hope, resilience and optimism.

\section{Abbreviations}

PsyCap: Psychological Capital; PCQ-C: Psychological Capital Questionnaire for cancer patients; WHO: World Health Organization; CD-RISC: Connor Davidson Resilience Scale; PHQ-9: Patient Health Questionnaire-9; GAD-7: Generalized Anxiety Disorder-7; EFA: Exploratory factor Analysis; KMO: Kaiser-Meyer-Olkin; CFA: Confirmatory Factor Analysis

\section{Acknowledgments \\ All authors would like to gratitude the research fellows who participate in data collection, management and analysis of the study. All authors read and approved the final manuscript.}

\section{Authors' contributions}

CYC and LW conceived and designed the survey. CYC, YW and YZ performed the investigation. CYC, SQC and NJ analyzed the data. CYC wrote the original paper. LW revised the paper. All authors read and approved the final manuscript.

\section{Funding}

There was no funding support.

\section{Availability of data and materials}

The dataset in this study is available from the corresponding author on reasonable request.

\section{Declarations}

Ethics approval and consent to participate

The study was approved by the Ethics Committee on Human Experimentation of China Medical University, and the study procedures were in accordance with ethical standards. All patients provided their written informed consent prior to responding to the survey.

The study was in accordance with Declaration of Helsinki.

\section{Consent for publication}

Not applicable.

\section{Competing interests}

There are no competing interests.

Received: 4 July 2021 Accepted: 3 November 2021

Published online: 10 November 2021

References

1. Pitichat T, Reichard RJ, Kea-Edwards A, Middleton E, Norman SM. Psychological Capital for Leader Development. J Leadersh Org Stud. 2018; 25(1):47-62. https://doi.org/10.1177/1548051817719232.

2. Bao Y, Li L, Guan Y, Wang W, Liu Y, Wang P, et al. Prevalence and associated positive psychological variables of anxiety and depression among patients with central nervous system tumors in China: a cross-sectional study. Psycho-oncology. 2017;26(2):262-9. https://doi.org/10.1002/pon.4128. 
3. Luthans F, Youssef CM, Avolio BJ. Psychological capital. New York: Oxford University Press. Page 3. 2007.

4. Luthans F, Youssef CM. Emerging positive organizational behavior. J Manag. 2007;33(3):321-49. https://doi.org/10.1177/0149206307300814.

5. MacDonald C, Theurer JA, Fung K, Yoo J, Doyle PC. Resilience: an essential element in head and neck cancer survivorship and quality of life. Support Care Cancer. 2020;17(7):3725-33. https://doi.org/10.1007/s00520-02005873-4.

6. Lin CC, Tsay HF. Relationships among perceived diagnostic disclosure, health locus of control, and levels of hope in Taiwanese cancer patients. Psycho-oncology. 2005;14(5):376-85. https://doi.org/10.1002/pon.854.

7. Leung J, Atherton I, Kyle RG, Hubbard G, McLaughlin D. Psychological distress, optimism and general health in breast cancer survivors: a data linkage study using the Scottish health survey. Support Care Cancer. 2016; 24(4):1755-61. https://doi.org/10.1007/s00520-015-2968-2.

8. Moreno PI, Ramirez AG, San Miguel-Majors SL, Fox RS, Castillo L, Gallion KJ, et al. Satisfaction with cancer care, self-efficacy, and health-related quality of life in Latino cancer survivors. Cancer. 2018;124(8):1770-9. https://doi.org/1 $0.1002 /$ cncr.31263

9. Sung H, Ferlay J, Siegel RL, Laversanne M, Soerjomataram I, Jemal A, et al. Global Cancer statistics 2020: GLOBOCAN estimates of incidence and mortality worldwide for 36 cancers in 185 countries. CA Cancer J Clin. 2021; 71(3):209-49. https://doi.org/10.3322/caac.21660.

10. Hill J, Holcombe C, Clark L, Boothby MR, Hincks A, Fisher J, et al. Predictors of onset of depression and anxiety in the year after diagnosis of breast cancer. Psychol Med. 2011 Jul;41(7):1429-36. https://doi.org/10.1017/500332 91710001868

11. Fischer IC, Cripe LD, Rand KL. Predicting symptoms of anxiety and depression in patients living with advanced cancer: the differential roles of hope and optimism. Support Care Cancer. 2018;26(10):3471-7. https://doi. org/10.1007/s00520-018-4215-0

12. Gao Y, Yuan L, Pan B, Wang L. Resilience and associated factors among Chinese patients diagnosed with oral cancer. BMC Cancer. 2019;19(1):447. https://doi.org/10.1186/s1 2885-019-5679-0.

13. Harms CA, Cohen L, Pooley JA, Chambers SK, Galvão DA, Newton RU. Quality of life and psychological distress in cancer survivors: the role of psycho-social resources for resilience. Psycho-oncology. 2019;28(2):271-7. https://doi.org/10.1002/pon.4934.

14. Yang YL, Liu L, Li MY, Shi M, Wang L. Psychological disorders and psychosocial resources of patients with newly diagnosed bladder and kidney Cancer: a cross-sectional study. PLoS One. 2016;11(5):e0155607. https://doi.org/10.1371/journal.pone.0155607.

15. Redlich-Amirav D, Ansell LJ, Harrison M, Norrena KL, Armijo-Olivo S. Psychometric properties of Hope scales: a systematic review. Int I Clin Pract. 2018;72(7):e13213. https://doi.org/10.1111/ijcp.13213.

16. Ahern NR, Kiehl EM, Sole ML, Byers J. A review of instruments measuring resilience. Issues Compr Pediatr Nurs. 2006;29(2):103-25. https://doi.org/10.1 080/01460860600677643.

17. Connor KM, Davidson JR. Development of a new resilience scale: the Connor-Davidson resilience scale (CD-RISC). Depress Anxiety. 2003;18(2):7682. https://doi.org/10.1002/da.10113.

18. Snyder CR, Harris C, Anderson JR, Holleran SA, Irving LM, Sigmon ST, et al. The will and the ways: development and validation of an individualdifferences measure of hope. J Pers Soc Psychol. 1991;60(4):570-85. https:// doi.org/10.1037//0022-3514.60.4.570.

19. Snyder CR, Sympson SC, Ybasco FC, Borders TF, Babyak MA, Higgins RL. Development and validation of the state Hope scale. J Pers Soc Psychol. 1996;70(2):321-35. https://doi.org/10.1037//0022-3514.70.2.321.

20. Deshields TL, Heiland MF, Kracen AC, Dua P. Resilience in adults with cancer: development of a conceptual model. Psycho-oncology. 2016;25(1): 11-8. https://doi.org/10.1002/pon.3800.

21. Ye ZJ, Liang MZ, Li PF, Sun Z, Chen P, Hu GY, et al. New resilience instrument for patients with cancer. Qual Life Res. 2018;27(2):355-65. https://doi.org/10.1007/s11136-017-1736-9.

22. Merluzzi TV, Martinez Sanchez MA. Assessment of self-efficacy and coping with cancer: development and validation of the Cancer behavior inventory. Heal Psychol American Psychological Association. 1997;16(2):163-70. https:// doi.org/10.1037/0278-6133.16.2.163

23. Luthans F, Avolio BJ, Avey JB, Norman SM. Positive psychological capital: measurement and relationship with performance and satisfaction. Pers Psychol. 2007;60(3):541-72. https://doi.org/10.1111/j.1744-6570.2007.00083.x.
24. Yu X, Tam WW, Wong PT, Lam TH, Stewart SM. The patient health Questionnaire-9 for measuring depressive symptoms among the general population in Hong Kong. Compr Psychiatry. 2012;53(1):95-102. https://doi. org/10.1016/j.comppsych.2010.11.002

25. Tong X, An D, McGonigal A, Park SP, Zhou D. Validation of the generalized anxiety Disorder-7 (GAD-7) among Chinese people with epilepsy. Epilepsy Res. 2016;120:31-6. https://doi.org/10.1016/j.eplepsyres.2015.11.019.

26. Field AP. Discovering statistics using SPSS. Los Angeles; London: Sage; 2009.

27. Chen TF, Chou KR, Liao YM, Ho CH, Chung MH. Construct validity and reliability of the Chinese version of the disaster preparedness evaluation tool in Taiwan. J Clin Nurs. 2015;24(7-8):1132-43. https://doi.org/10.1111/ jocn.12721.

28. Byrne BM. Structural equation modeling with AMOS: basic concepts, applications, and programming. Mahwah, NJ: Erlbaum; 2001.

29. Polit DF, Beck CT. Essentials of nursing research: appraising evidence for nursing practice. 8th ed. Philadelphia: Lippincott Williams and Wilkins; 2013.

30. Bentler PM. Comparative fit indices in structure models. Psychol Bull. 1990; 107(2):238-46. https://doi.org/10.1037/0033-2909.107.2.238.

31. Hu L, Bentler PM. Cutoff criteria for fit indexes in covariance structure analysis: conventional criteria versus new alternatives. Struct Equ Model. 1999;6(1):1-55. https://doi.org/10.1080/10705519909540118.

32. Hair JF, Black WC, Babin BJ, Anderson RE. Multivariate data analysis: a global perspective. 7th ed. Prentice Hall: Pearson Education International; 2010.

33. Sadia M, Aaisha S. Impact of Cancer-related fatigue on psychological semiology among Cancer patients. Pak J Med Res. 2018;57(1):20-3.

34. Dufault K, Martocchio BC. Symposium on compassionate care and the dying experience. Hope: its spheres and dimensions. Nurs Clin North Am. 1985;20(2):379-91.

35. Luszczynska A, Scholz U, Schwarzer R. The general self-efficacy scale: multicultural validation studies. J Psychol. 2005;139(5):439-57. https://doi. org/10.3200/JRLP.139.5.439-457.

36. Min JA, Yoon S, Lee CU, Chae JH, Lee C, Song KY, et al. Psychological resilience contributes to low emotional distress in cancer patients. Support Care Cancer. 2013;21 (9):2469-76. https://doi.org/10.1007/s00520-013-1807-6.

37. Carver CS, Scheier MF. Dispositional optimism. Trends Cogn Sci. 2014;18(6): 293-9. https://doi.org/10.1016/j.tics.2014.02.003.

38. Carver CS, Scheier MF, Segerstrom SC. Optimism. Clin Psychol Rev. 2010 Nov:30(7):879-89. https://doi.org/10.1016/j.cpr.2010.01.006.

39. Abu Bakar N, Torkamani M, Tanprawate S, Lambru G, Matharu M, Jahanshahi $M$. The development and validation of the cluster headache quality of life scale (CHQ). J Headache Pain. 2016;17(1):79. https://doi.org/10.1186/s10194016-0674-1.

\section{Publisher's Note}

Springer Nature remains neutral with regard to jurisdictional claims in published maps and institutional affiliations.

\section{Ready to submit your research? Choose BMC and benefit from:}

- fast, convenient online submission

- thorough peer review by experienced researchers in your field

- rapid publication on acceptance

- support for research data, including large and complex data types

- gold Open Access which fosters wider collaboration and increased citations

- maximum visibility for your research: over $100 \mathrm{M}$ website views per year

At $\mathrm{BMC}$, research is always in progress.

Learn more biomedcentral.com/submissions 